\title{
Novel Oxazabicycles as a New Class of Photochromic Colorants
}

\author{
Ding-Yah Yang, ${ }^{*}, \dagger$ You-Sheng Chen, ${ }^{\dagger}$ Pei-Yu Kuo, ${ }^{\dagger}$ Jiun-Ting Lai, ${ }^{\dagger}$ \\ Chang-Ming Jiang, ${ }^{\ddagger}$ Chin-Hung Lai, ${ }^{\ddagger}$ Yong-Hong Liao, ${ }^{\ddagger}$ and Pi-Tai Chou ${ }^{\star, \neq}$ \\ Department of Chemistry and Center for Nanoscience and Technology, Tunghai \\ University, Taichung 407, Taiwan, and Department of Chemistry, National Taiwan \\ University, Taipei 106, Taiwan \\ yang@thu.edu.tw; chop@ntu.edu.tw
}

Received October 11, 2007

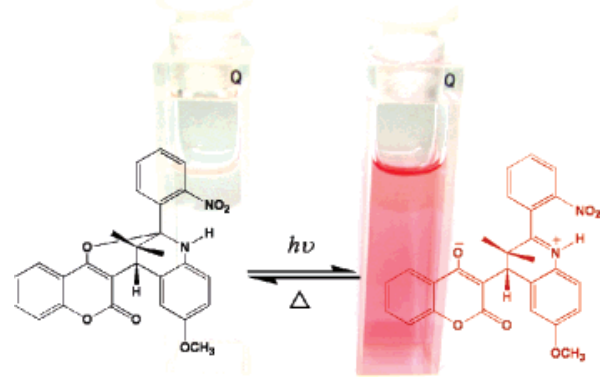

A new photochromic colorant with an oxazabicyclic moiety has been synthesized by an efficient method. It turns pale red upon UV irradiation and undergoes reverse reaction while being heated. This work may open an exciting new avenue for future development of the photochromic dyes with novel molecular structures.

Owing to their practical applications in ophthalmic lenses, organic photochromic dyes have long attracted great attention. ${ }^{1,2}$ Extensive investigations have been carried out on bisdiarylethenes, ${ }^{3}$ bispyrans, ${ }^{4}$ bisbenzodihydropyrenes,,${ }^{5}$ and bishydroindolizines. ${ }^{6}$ While modifications of the existing photochromes may still generate compounds with unprecedented properties, new classes of organic photochromic dyes with novel molecular structures should be developed for use as suitable materials for optical memory media, photooptical switch components, and other applications.

In our continuing efforts to develop new therapeutic agents for anti-coagulation therapy in humans by inhibiting the activity of vitamin $\mathrm{K}$ 2,3-epoxide reductase (VKOR), we recently discovered a conformationally restricted VKOR inhibitor with a coumarin-containing dioxobicyclic and oxazabicyclic skeleton. ${ }^{7}$ Upon ultraviolet irradiation of oxazabi-

\footnotetext{
Tunghai University.

$\doteqdot$ National Taiwan University.

(1) Crano, J. C.; Guglielmetti, R. J. Organic Photochromic and Thermochromic Compounds; Plenum Press: New York, 1999.

(2) (a) Willner, I. Acc. Chem. Res. 1997, 30, 347-356. (b) Feringa, B. L. Molecular Switches; Wiley-VCH: Weinheim, Germany, 2001. (c) Duerr, H.; Bouas-Laurent, H. Photochromism: Molecules and Systems; Elsevier: Amsterdam, 2003.
}

cycle 1 (see Scheme 1), a mixture of quinoline-containing derivatives $\mathbf{2}$ and $\mathbf{3}$ as well as 4-hydroxycoumarin were detected. This result suggested that the photoreaction of $\mathbf{1}$ should involve a $\mathrm{C}-\mathrm{O}$ bond cleavage at the junction of the two heterocycles, along with a subsequent aromatization.

(3) (a) Higashiguchi, K.; Matsuda, K.; Irie, M. Angew. Chem., Int. Ed. 2003, 42, 3537-3540. (b) Kobatake, S.; Irie, M. Tetrahedron 2003, 59, 8359-8364. (c) Matsuda, K.; Irie, M. J. Am. Chem. Soc. 2001, 123, 98969897. (d) Chen, B. Z.; Wang, M. Z.; Luo, Q. F.; Tian, H. Synth. Met. 2003, 137, 985-987. (e) Luo, Q.; Chen, B.; Wang, M.; Tian, H. Adv. Funct. Mater. 2003, 13, 233-239. (f) Higashiguchi, K.; Matsuda, K.; Tanifuji, N.; Irie, M. J. Am. Chem. Soc. 2005, 127, 8922-8923.

(4) (a) Zhao, W.; Carreira, E. M. Org. Lett. 2006, 8, 99-102. (b) Zhao, W.; Carreira, E. M. J. Am. Chem. Soc. 2002, 124, 1582-1583. (c) Yassar, A.; Rebiere-Galy, N.; Frigoli, M.; Moustrou, C.; Samat, A.; Guglielmetti, R.; Jaafari, A. Synth. Met. 2001, 124, 23-27. (d) Yassar, A.; Jaafari, H.; Rebiere-Galy, N.; Frigoli, M.; Moustrou, C.; Samat, A.; Guglielmetti, R. Eur. Phys. J. Appl. Phys. 2002, 18, 3-8.

(5) (a) Mitchell, R. H.; Bandyopadhyay, S. Org. Lett. 2004, 6, 17291732. (b) Mitchell, R. H.; Ward, T. R.; Chen, Y.; Wang, Y.; Weerawarna, S. A.; Dibble, P. W.; Marsella, M. J.; Almutair, A.; Wang, Z. Q. J. Am. Chem. Soc. 2003, 125, 2974-2988. (c) Mitchell, R. H.; Ward, T. R.; Wang, Y.; Dibble, P. W. J. Am. Chem. Soc. 1999, 121, 2601-2602.

(6) Bleisinger, H.; Scheidhauer, P.; Dürr, H.; Wintgens, V.; Valat, P.; Kossanyi, J. J. Org. Chem. 1998, 63, 990-1000.

(7) (a) Chen, D.-U.; Kuo, P.-Y.; Yang, D.-Y. Bioorg. Med. Chem. Lett. 2005, 15, 2665-2668. (b) Wang, J.-F.; Liao, Y.-X.; Kuo, P.-Y.; Gau, Y.H.; Yang, D.-Y. Synlett 2006, 17, 2791-2794. 
Scheme 1. Photodissociation of Oxazabicycle 1 upon UV Irradiation

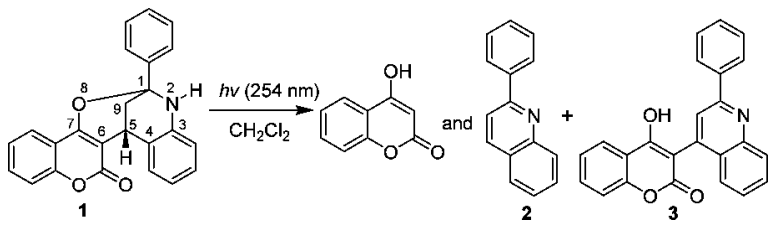

We thus speculate that this skeleton may have the potential to function as a new class of photochromic systems if the subsequent aromatization process can be prohibited. As for a strategic design, incorporation of two alkyl groups (i.e., dimethyl groups) at the $\mathrm{C}(9)$-position of this oxazabicyclic skeleton may prevent the undesired aromatization reaction upon UV irradiation. Herein, we report the efficient synthesis of novel oxazabicycles $\mathbf{7 a}-\mathbf{e}$, in which $\mathbf{7} \mathbf{c}$ is demonstrated to represent a new class of photochromic colorant.

Scheme 2 shows the preparation of gem-dimethyl-substituted oxazabicycles $7 \mathbf{a}-\mathbf{e}$. It began with a $\mathrm{MgSO}_{4}$-mediated

Scheme 2. Preparation of Gem-Dimethyl-Substituted Oxazabicycles $7 \mathbf{a}-\mathbf{e}$
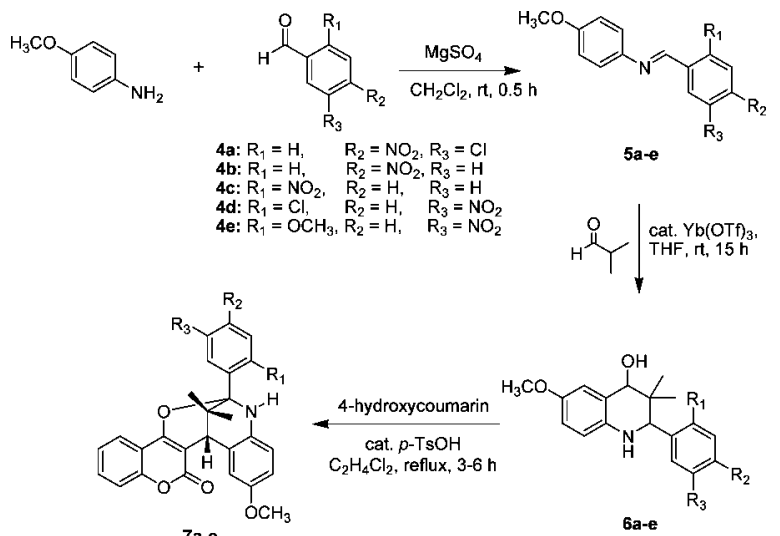

7a-e

6a-e

condensation of $p$-anisidine and substituted benzaldehydes $\mathbf{4 a}-\mathbf{e}$ to afford the imines $\mathbf{5 a}-\mathbf{e}$, followed by a $\mathrm{Yb}(\mathrm{OTf})_{3^{-}}$ catalyzed coupling with isobutyraldehyde to give the cyclized alcohols $\mathbf{6 a}-\mathbf{e} .^{8}$ The reaction of $\mathbf{6 a}-\mathbf{e}$ with 4 -hydroxycoumarin in the presence of a catalytic amount of $p$-toluenesulfonic acid under reflux conditions yielded the target compounds $\mathbf{7 a}-\mathbf{e}$ (see Supporting Information for detailed characterization). The aforementioned three reaction steps could all be acid-catalyzed, and the bond formation during the construction of the bicyclic skeleton was highly efficient.

Among the prepared compounds, the oxazabicycle 7c, which contained a nitro substituent at the ortho position of the bridgehead benzene ring, exhibited salient photochromic behavior. Upon ultraviolet irradiation $(320 \mathrm{~nm})$, the oxazabicycle 7c in $\mathrm{CH}_{3} \mathrm{CN}$ turned from colorless to pale red, as

(8) Annunziata, R.; Cinquini, M.; Cozzi, F.; Molteni, V.; Schupp, O. Tetrahedron 1997, 53, 9715-9726. shown in the graphic abstract. Spectroscopically, with the increase of exposure time, a new absorption band with the peak wavelength around $500 \mathrm{~nm}$ gradually increased. Although an isosbestic point was lacking during photolysis, the absorbance at $500 \mathrm{~nm}$ showed a smooth, continuous growth and reached a plateau (see inset of Figure 1), implying the stationary conversion to the $500 \mathrm{~nm}$ absorbing species.

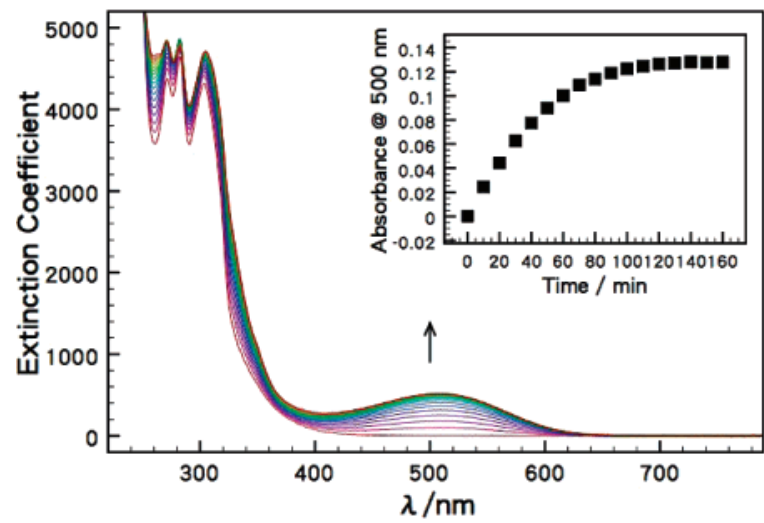

Figure 1. Absorption spectra of $7 \mathbf{c}$ in $\mathrm{CH}_{3} \mathrm{CN}$ obtained with different exposure times, 0 to $160 \mathrm{~min}$, with increments of $10 \mathrm{~min}$. Inset: Increase of absorbance at $500 \mathrm{~nm}$ with respect to irradiating time.

Isolation of the photogenerated product proved to be difficult since it reverted easily back to the original form under weakly acidic conditions on the silica gel column. Alternatively, upon methylation of the photogenerated product with diazomethane, the resulting methylated derivative 8 was stable enough to be isolated for further characterization (Scheme 3). The X-ray crystal structure of 8 (see Figure S1 in the Supporting Information) clearly presents the similarities to $\mathbf{7 c}$ in its mainframe, except for the cleavage of the $\mathrm{O}(8)-\mathrm{C}(1)$ bond (see Scheme 1 for the numerical sequence, which is renamed to the $\mathrm{O}(3)-\mathrm{C}(17)$ bond in Figure $\mathrm{S} 1$ ) in the oxazabicyclic moiety and the methylation at the $\mathrm{O}(8)$ site (see Scheme 3). The results lead us to conclude that 7c may simply undergo the $\mathrm{O}(8)-\mathrm{C}(1)$ bond

Scheme 3. The Photochromic Properties and Related Structures of Compound 7c

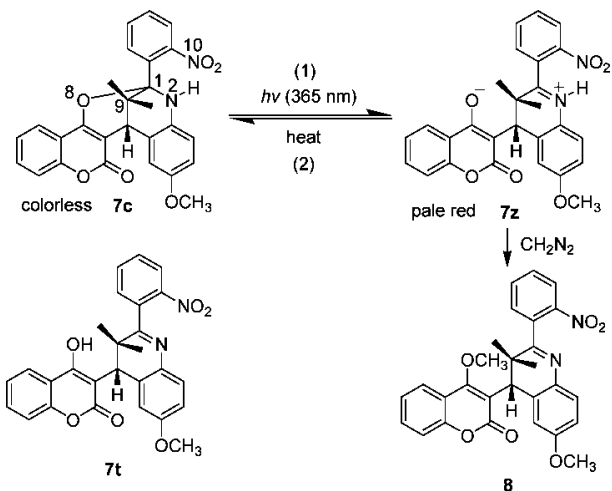


cleavage upon electronic excitation, presumably forming a zwitterionic species 7z (see Scheme 3, vide infra).

In the dark, the proposed ring-opened form $7 \mathbf{z}$ in $\mathrm{CH}_{3} \mathrm{CN}$ thermally decays away with the disappearance (i.e., turning colorless) of the $500 \mathrm{~nm}$ band, as shown in Figure 2a. Upon UV (e.g., $320 \mathrm{~nm}$ ) irradiation of the colorless product, the photoproduct turns pale red again with the appearance of the $500 \mathrm{~nm}$ band characteristics for $\mathbf{7 z}$. The results support the thermally assisted $\mathbf{7 z} \rightarrow \mathbf{z} \mathbf{c}$ reverse ring-closure process. To gain more insight into the corresponding photochromism, the reverse $\mathbf{7 z} \rightarrow \mathbf{z}$ c reaction was carried out at various temperatures, and the decay kinetics of $\mathbf{7} \mathbf{z}$ were monitored with the $500 \mathrm{~nm}$ absorbance, $A$, as a function of the monitoring time. The first-order decay dynamics are supported by a straight line plot of $\ln A$ versus time at various temperatures (Figure 2b). Taking $k_{\text {rev }}$ to be the rate constant for the $7 \mathbf{z} \rightarrow 7 \mathbf{c}$ reaction, an Arrhenius plot of $\ln k_{\text {rev }}$ as a function of $1 / T$ reveals a straight line (see inset of Figure 2b). Accordingly, an activation energy and frequency factor of $14.2 \mathrm{kcal} / \mathrm{mol}$ and $2.1 \times 10^{6} \mathrm{~s}^{-1}$ is deduced. The relatively small frequency factor implies that the reverse reaction (i.e., the cyclization bond formation) involves specific reorientation and hence a large reduction of the entropy factor. It is
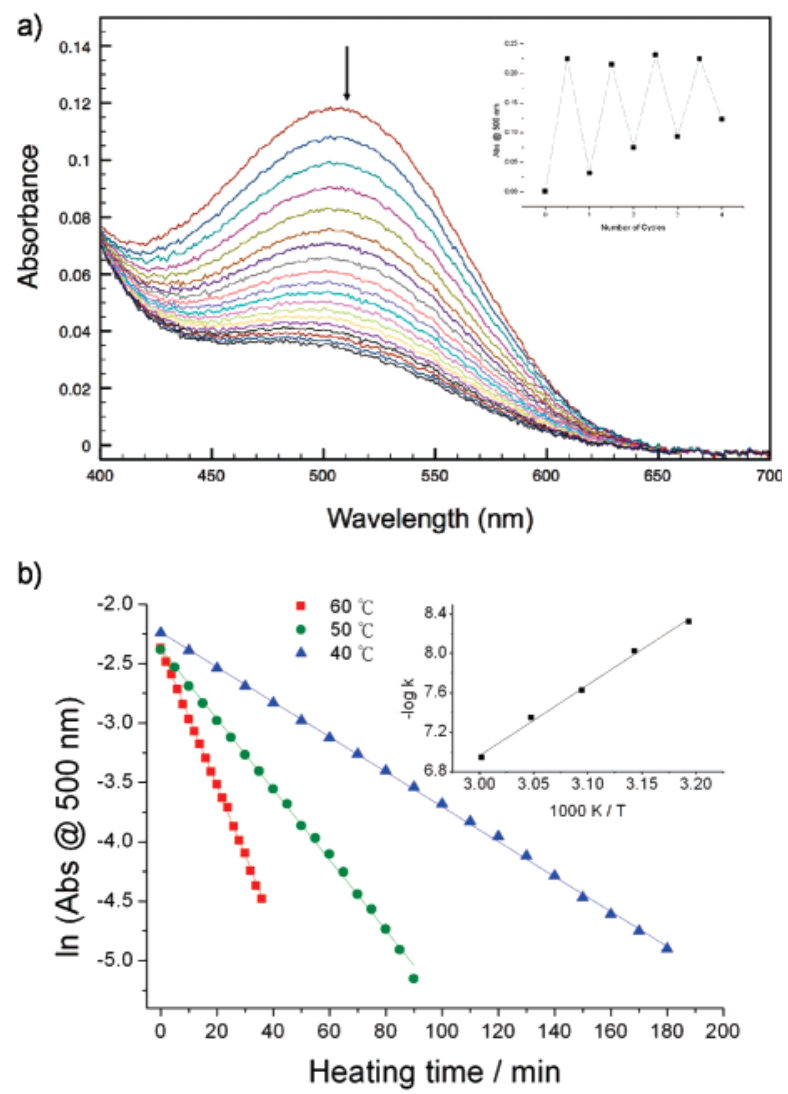

Figure 2. (a) Thermal bleaching of $7 \mathbf{z}$ (in $\mathrm{CH}_{3} \mathrm{CN}$ ) around 500 $\mathrm{nm}$ at $60{ }^{\circ} \mathrm{C}$ from 0 to $36 \mathrm{~min}$ with increments of $2 \mathrm{~min}$. Inset: Absorbance at $500 \mathrm{~nm}$ in the first four cycles, in which each cycle consists of $3 \mathrm{~h} \mathrm{UV}$ irradiation and 90 min thermal bleaching at $60{ }^{\circ} \mathrm{C}$. (b) The plot of $\ln A_{500 \mathrm{~nm}}$ versus decay time at various temperatures. Inset: The plot of $\ln k_{\text {rev }}$ versus $1 / T$. also noteworthy that when irradiating the product $7 \mathbf{z}$ by 500 $\mathrm{nm}$ light $\left(5 \mathrm{~mW} / \mathrm{cm}^{2}\right)$ for a period of $3 \mathrm{~min}$, which is much shorter than the $\mathbf{7 z} \rightarrow \mathbf{7 c}$ thermal recovery time at $298 \mathrm{~K}$, nearly no change of the spectrum was observed, indicating that $\mathbf{7 z}$ is not transformed into $\mathbf{7 c}$ upon electronic excitation.

During the thermal recovery process, we noticed that the absorbance around $500 \mathrm{~nm}$ after the thermal bleaching did not return to zero as the product $7 \mathbf{c}$ should have (see Figures 1 and 2 a for comparison). Under the same photolysis period, the same residual absorbance was observed upon performing the $\mathbf{7 z} \rightarrow \mathbf{7 c}$ process in various temperatures ranging from 20 to $60{ }^{\circ} \mathrm{C}$. We thus discarded the possibility of thermal equilibrium between $\mathbf{7 c}$ and $\mathbf{7 z}$, concluding instead the generation of side products. This viewpoint is also supported by a theoretical approach, in which $7 \mathbf{c}$ is more stable than 7z (zwitterionic form) by $>30 \mathrm{kcal} / \mathrm{mol}$ (vide infra). The temperature-independent side product formation during the reverse $\mathbf{7 z} \rightarrow \mathbf{7}$ c reaction also eliminates the possibility of its origin being thermal decomposition of $\mathbf{7 z}$. Instead, the side product was produced during the photoinduced $7 \mathbf{c} \rightarrow$ $7 \mathbf{z}$ process. In addition to the major $\mathbf{7 z}$ formation, it is plausible that, similar to the ultraviolet irradiation of oxazabicycle $\mathbf{1}$, the photoreaction of $\mathbf{7 c}$, at a small percentage, involves a $\mathrm{C}-\mathrm{O}$ bond cleavage at the junction of the two heterocycles, along with a subsequent aromatization. Being solely dependent on the change of $500 \mathrm{~nm}$ absorbance from $\mathbf{7 z}$, the first four (1) $\rightarrow(2) \rightarrow(1)$ (see Scheme 3 ) cycles are depicted in the inset of Figure 2a. After the fourth cycle, the $\mathbf{7 z}$ production decreases to $\sim 50 \%$ of its first photoconversion.

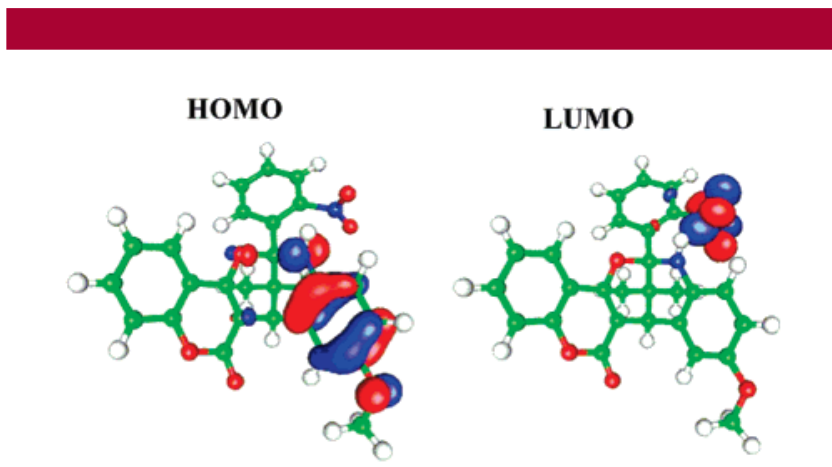

Figure 3. The HOMO/LUMO of 7c.

To gain further insight into the reaction thermodynamics, we carried out a molecular simulation utilizing the density function theory (DFT) method. Under the full geometry optimization (B3LYP/6-31G*), ${ }^{9}$ 7c was calculated to be lower in energy than $\mathbf{7 z}$ by $34.83 \mathrm{kcal} / \mathrm{mol}$. Applying the TDMPW1K method, ${ }^{10,11}$ the $\mathrm{S}_{0} \rightarrow \mathrm{S}_{1}$ transitions were calculated to be $28090(356 \mathrm{~nm})$ and $13158 \mathrm{~cm}^{-1}(760 \mathrm{~nm})$ for $7 \mathbf{c}$ and $\mathbf{7 z}$, respectively, the results of which, especially for $\mathbf{7 z}$, are significantly lower in energy than the respective peak wavelength at $\sim 310$ and $\sim 500 \mathrm{~nm}$ extracted from the absorption spectroscopy. For further improvement, using IEFPCM model (see Supporting Information) to consider the solvent effect of acetonitrile, ${ }^{12}$ the $S_{0} \rightarrow S_{1}$ transition of $7 \mathbf{z}$ is shifted from 13158 to $18762 \mathrm{~cm}^{-1}(533 \mathrm{~nm})$, while it 
remains nearly unchanged for $7 \mathbf{c}(350 \mathrm{~nm})$. The large solvation change in $\mathbf{7 z}$ further implies its zwitterionic property. According to the calculation, the electronic excitation between $S_{0}$ and $S_{1}$ of $7 c$ is dominated by the HOMO $\rightarrow$ LUMO excitation (Figure 3), in which the electron density of HOMO is mainly located on the lone pair of $\mathrm{O}(8)$ atoms and the $p$-methoxybenzamine moiety. Conversely, the electron density is transferred to the $\mathrm{NO}_{2}$ group in the LUMO. The net change of the electron density during the HOMO $\rightarrow$ LUMO transition is expected to cause the $\mathrm{C}-\mathrm{O}$ bond weakening and consequently cleavage. We also performed a similar calculation on $\mathbf{7 t}$, considered to be another possible neutral product (see Scheme 3 ). The calculated $S_{0} \rightarrow S_{1}$ transition of $28570 \mathrm{~cm}^{-1}(350 \mathrm{~nm})$ is much higher in energy than that of the product $(\mathbf{7 z})$ absorption peak experimentally resolved to be $500 \mathrm{~nm}$. The result justifies the assignment of $\mathbf{7 z}$ to a zwitterionic species, Theoretically, the $\mathbf{7 c} \rightarrow \mathbf{7 z}$ formation involves only the cleavage of $\mathrm{C}\left(\mathrm{sp}^{3}\right)-\mathrm{O}$ bonding at the junction of the heterobicycle, while for $\mathbf{7 t}$, if it were the photoproduct, in addition to the bond cleavage, another hydrogen transfer from $\mathrm{N}$ to $\mathrm{O}$ would be necessary, leading to a dynamically unfavorable pathway.

Among $\mathbf{7 a}-\mathbf{e}$ only $\mathbf{7 c}$ exhibits the aforementioned photochromic properties. The fact that only the oxazabicycle with a nitro substituent at the ortho position of the bridgehead benzene ring exhibited the expected photochromic behavior implied that the ortho substituent, but not meta and para, on the bridgehead benzene ring plays an important role in the photochemistry. We initially speculated that the increasing steric hindrance between the ortho substituent and the nearby methyl groups on the heterobicyclic skeleton made $7 \mathbf{c}$ more susceptible to a $\mathrm{C}-\mathrm{O}$ bond rupture than the corresponding $p$-nitro-substituted $\mathbf{7 b}$. However, neither the $o$-chloro-functionalized (7d) nor the $o$-methoxy-substituted (7e) analogue exhibits any photochromic behavior, suggesting that factors other than the steric effect govern the photochromism. An additional experiment was also performed and found no photochromic property when the amino group $(\mathrm{N}(2))$ on $7 \mathrm{c}$ was methylated. The result thus drew our attention on the possible role of hydrogen bonding formation between the iminium hydrogen $(\mathrm{N}(2)-\mathrm{H})$ and nitrooxygen $(\mathrm{N}(10)-\mathrm{O})$. The result of molecular simulation for 7c produced an estimated distance between the oxygen atom on the $o$-nitro group and the amino hydrogen atom of $2.39 \AA$ (see Figure $\mathrm{S} 2$ in the Supporting Information), while this distance for $7 \mathbf{z}$ even decreases to as short as $1.98 \AA$. It is thus reasonable to propose that $\mathbf{7 z}$ can be further stabilized via enhancing the intramolecular hydrogen bonding strength between the iminium hydrogen and the nitrooxygen. This hypothesis is supported by the result that $\mathbf{7 z}$ is calculated to be $34.2 \mathrm{kcal} /$ mol (adding $\mathrm{CH}_{3} \mathrm{CN}$ as the solvent) higher in energy than 7c, while based on a similar method, we calculated the energy of zwitterionic product of $\mathbf{7 b}$, if there were any, to be higher in energy than $\mathbf{7 b}$ by $39.3 \mathrm{kcal} / \mathrm{mol}$. In comparison, the difference of $\sim 5 \mathrm{kcal} / \mathrm{mol}$ manifests the stabilization energy given by the hydrogen bonding formation in $\mathbf{7 z}$. We thus tentatively propose that the strong $\mathrm{N}(2)-\mathrm{H}-\mathrm{O}-\mathrm{N}(10)$ intramolecular hydrogen bonding plays a certain role in "trapping" the $\mathbf{7 z}$ species. Note that similar hydrogen bonding formation is not evident in other synthesized analogues presented in this study.

We have also made attempts to analyze the product yield in a more quantitative manner. Using a $30 \mathrm{~mW} / \mathrm{cm}^{2} 355 \mathrm{~nm}$ $\mathrm{Nd}$ :YAG pulse laser to illuminate the entire volume of 3 $\mathrm{mL}$ of $7 \mathrm{c}$ solution $\left(7.8 \times 10^{-5} \mathrm{M}\right.$ in acetonitrile) for 100 min, we then observed that the absorbance at $500 \mathrm{~nm}$ was increased from 0.003 to 0.172 , corresponding to an increase of $4.9 \times 10^{-5} \mathrm{M}$ of the $7 \mathbf{z}$ production. Taking the ratio of the number of $\mathbf{7 z}$ molecules being produced versus the number of photons being absorbed, the yield of $7 \mathbf{z}$ production was then estimated to be $0.12 \pm 0.02 \%$.

Since the above photochromic phenomena, the associated dynamics, and efficiency are independent of $\mathrm{O}_{2}$, the reaction less likely takes place in the triplet manifold. To draw the relative thermodynamics in the excited singlet state, we simply added the observed $\mathrm{S}_{0} \rightarrow \mathrm{S}_{1}$ absorption peak in terms of energy to the calculated energy for $\mathbf{7 c}$ and $\mathbf{7 z}$. The result, depicted in Scheme 4 of the Supporting Information, indicates that $\mathbf{7 c} \rightarrow \mathbf{7 z}$ is thermodynamically favorable only by $\sim 1.0 \mathrm{kcal} / \mathrm{mol}$ along the $\mathrm{S}_{1}$ state. Alternatively, it is more plausible that the photochromism proceeds via a nonadiabatic (i.e., surface crossing) process from $S_{1}(\mathbf{7 c})$ to $S_{0}(\mathbf{7 z})$. Nevertheless, at this stage, whether the reaction takes place strictly in the excited state or via crossing to the ground state potential energy surface is pending detailed dynamics approaches.

The oxazabicycle 7c reported here, to the best of our knowledge, represents the first example of a heterobicyclic molecule exhibiting satisfactory photochromic properties. Although the overall photochromism cycle is relatively slow and the maximum absorption at $500 \mathrm{~nm}\left(\epsilon \sim 500 \mathrm{M}^{-1} \mathrm{~cm}^{-1}\right.$, see Figure 1) is low, we believe that $7 \mathbf{c}$ or its analogues may still merit future applications. For example, the $\mathbf{7 z} \rightarrow \mathbf{7 c}$ reverse reaction is of importance in that the $\sim 34 \mathrm{kcal} / \mathrm{mol}$ is chemically stored in $\mathbf{7 z}$ and may be re-exploited in the presence of suitable catalysts. Moreover, in the current system, both $\mathbf{7 c}$ and $\mathbf{7 z}$ are nonluminescent despite their anchoring coumarin moiety. Thus, work focusing on the improvement of the reaction reversibility as well as the utilization of fluorescence based on coumarin analogues to enhance the detection should be of great interest. We thus believe that this work may open an exciting new avenue for future development of the photochromic dyes with novel molecular structures.

Acknowledgment. We thank the National Science Council, Taiwan, for financial support.

Supporting Information Available: Additional experimental details. This material is available free of charge via the Internet at http://pubs.acs.org.

OL702482C

(9) Koné, M.; Illien, B.; Graton, J.; Laurence, C. J. Phys. Chem. A 2005 109, 11907-11913.

(10) Dutoi, A. D.; Head-Gordon, M. Chem. Phys. Lett. 2006, 422, 230233.

(11) Lynch, B. J.; Fast, P. L.; Harris, M.; Truhlar, D. G. J. Phys. Chem. A 2000, 104, 4811-4815.

(12) Cancès, E.; Mennucci, B.; Tomasi, J. J. Chem. Phys. 1997, 107, $3032-3041$ 